\title{
Teratomatous Genotype Detected in Malignancies of a Non-Germ Cell Phenotype
}

\author{
Mojgan Devouassoux-Shisheboran, Alexander O. Vortmeyer, Susan A. Silver, \\ Zhengping Zhuang, and Fattaneh A. Tavassoli
}

Department of Gynecologic and Breast Pathology (MD-S, SAS, FAT), Armed Forces Institute of Pathology, Washington DC, and National Institute of Neurological Disorders and Stroke (AOV, ZZ), National Institutes of Health, Bethesda, Maryland

\begin{abstract}
SUMMARY: Originating from post-meiotic germ cells, mature ovarian teratomas (MOT) are genetically homozygous tumors within heterozygous hosts. MOT may be associated with malignant tumors of a non-germ cell phenotype (so-called malignant transformation). Based on the presence of in situ changes, some cases have been hypothesized to arise from teratomatous tissue. However, other malignancies associated with mature teratomas, such as sarcomas, may originate from either teratomatous elements or preexisting somatic ovarian tissue. Eight cases of MOT containing various histologic types of malignancy, including four squamous cell carcinomas, two sarcomas, one thyroid carcinoma, and one carcinoid tumor, were selected for study. Using selective tissue microdissection and PCR-based analysis of the extracted DNA, we compared the genotypic pattern of the mature teratomatous components to the associated malignant neoplasm with a random panel of highly informative genetic markers for different chromosomes. In all eight cases, genetic analysis of the malignant component revealed a homozygous genotype. In seven cases, the genetic profiles of mature teratomas and the associated malignant tumors were identical, suggesting a direct pathogenetic relationship between these lesions. In one case, the malignant component revealed homozygosity of different alleles compared with mature teratoma, suggesting independent teratomatous growth processes. This finding indicates that some ovarian malignancies of the non-germ cell phenotype arise in teratoma and fall into the spectrum of germ cell tumors. (Lab Invest 2000, 80:81-86).
\end{abstract}

$C$ omposed of one or several embryonic layers (ectoderm, endoderm, and mesoderm), mature teratoma is the most common ovarian germ cell tumor, accounting for $27 \%$ of all ovarian neoplasms in adults (Russel and Farnsworth, 1997). Tumors of a non-germ cell phenotype involving mature ovarian teratomas (MOT) are well recognized and include squamous cell carcinoma (Peterson, 1957), adenocarcinoma (Peterson, 1957), melanoma (Liberati et al, 1998), malignant lymphoma (Seifer et al, 1986), thyroid carcinoma (Devaney et al, 1993), sarcoma (Peterson, 1957), and carcinoid tumor (Kelley and Scully, 1961). Morphologically, different preneoplastic stages have been detected in some of these tumors (Hirakawa et al, 1989; Klionsky et al, 1972), suggesting that these malignancies may have originated from benign teratomatous tissue. This concept, however, has never been verified by comparative genetic analysis. Furthermore, in a subset of cases, preneoplastic changes cannot be identified and in such cases the morphologic examination alone is insufficient to determine whether the

Received October 5, 1999.

The opinions and assertions expressed herein are the private views of the authors and are not to be construed as official or as representing the views of the Department of the Army or the Department of Defense.

Address reprint requests to: Zhengping Zhuang, $M D, P h D, S N B / N I N D S$, NIH, Building 10, Room 5037, 9000 Rockville Pike, Bethesda, MD 20892. malignant component derives from teratomatous tissue or represents an independent non-teratomatous neoplastic growth.

To assess the pathogenetic relationship between MOT and associated malignancies, we undertook a genetic analysis of eight cases, using selective tissue microdissection of different mature teratomatous components and malignant lesions associated with the teratomas.

\section{Results}

Selectively microdissected tissue samples from MOTs and associated malignancies from eight women were procured for genetic analysis (Table 1, Fig. 1). From two to nine markers were informative, revealing the presence of both allelic bands (heterozygosity) in the normal tissue (ovarian stroma or fallopian tube) used as a control in all cases.

In cases 1 to 7 , each case revealed homozygous genotype in both teratomatous and malignant components with most informative markers (Figs. 2 to 4). In each case, homozygosity of the same allele was detected, when mature teratomatous tissue was compared with the malignant components. Occasionally, heterozygosity was detected in both the mature teratoma and malignant component of the tumors, as a result of meiotic recombination.

Case 8 consisted of two independent mature ovarian teratomas (MOT1 and MOT2) that were associated 
Table 1. Microdissected Tissue $\left({ }^{*}\right)$ Separately Analyzed from Eight Patients with Malignancies of Nongerm Cell Phenotype Involving Ovarian Teratomas

\begin{tabular}{|c|c|c|c|}
\hline & Site & Mature teratomatous components & Associated malignancy \\
\hline Case 1 & Right ovary & Squamous epithelium* & Squamous cell carcinoma* \\
\hline Case 2 & Right ovary & Squamous epithelium* & Squamous cell carcinoma* \\
\hline Case 3 & Right ovary & Squamous epithelium* & Squamous cell carcinoma* \\
\hline Case 4 & Left ovary & $\begin{array}{l}\text { Squamous epithelium* } \\
\text { Skin adnexal appendages, bone }\end{array}$ & Papillary thyroid carcinoma, follicular type* \\
\hline Case 5 & Right ovary & $\begin{array}{l}\text { Squamous epithelium* } \\
\text { Skin adnexal appendages } \\
\text { Respiratory epithelium, glia }\end{array}$ & Squamous cell carcinoma* \\
\hline Case 6 & Left ovary & $\begin{array}{l}\text { Prostate }^{*} \text {, cartilage } \\
\text { Respiratory epithelium } \\
\text { Gastrointestinal epithelium }\end{array}$ & Carcinoid tumor* \\
\hline Case 7 & Right ovary & $\begin{array}{l}\text { Squamous epithelium* } \\
\text { Skin adnexal appendages* }\end{array}$ & Rhabdomyosarcoma* \\
\hline \multirow[t]{3}{*}{ Case 8} & Right ovary & $\begin{array}{c}\text { MOT1:- } \\
\text { - Squamous epithelium* } \\
\text { MOT2:-Squamous epithelium* } \\
\text { - } \\
\text { - Thyroid* }\end{array}$ & $\begin{array}{l}\text { Angiosarcoma* } \\
\text { Angiosarcoma* }\end{array}$ \\
\hline & Left ovary & & Angiosarcoma* \\
\hline & Omentum & & Angiosarcoma* \\
\hline
\end{tabular}

with widely metastatic angiosarcoma. Genetic analysis revealed both teratomas to be homozygous, however, homozygosity of opposite alleles was observed with several markers suggesting independent origin of both teratomas. Angiosarcoma tissue from four different sites, including the right ovary adjacent to MOT1 and to MOT2, the left ovary, and the omental metastasis, was analyzed. All four sites yielded identical results and were consistently homozygous with all nine informative markers. However, different alleles were homozygous with several markers, when compared with MOT1 and MOT2 (Fig. 5).

\section{Discussion}

Malignant transformation, a well-recognized complication of MOT, occurs in less than $2 \%$ of cases (Kelley and Scully, 1961; Peterson, 1957). Some malignancies such as squamous cell carcinoma may arise from the epidermal component of the mature teratoma via carcinoma in situ (Klionsky et al, 1972) or from respiratory epithelium via squamous metaplasia/dysplasia/ carcinoma in situ (Hirakawa et al, 1989). However, in other cases, morphologic evidence for the transformation of benign ovarian teratomatous tissue into malignant neoplasm is lacking. It is not known whether such malignancies originate from ovarian somatic tissue or from teratomatous elements.

Comparative genetic studies of germ cell and nongerm cell tumors arising synchronously in the ovary have never been reported. A cytogenetic study demonstrating an $\mathrm{i}(12 \mathrm{p})$ in acute leukemias associated with mediastinal germ cell tumors is the only available genetic evidence supporting the germ cell origin of these hematologic malignancies (Ladanyi et al, 1990).

MOT can be associated with a variety of malignant tumors of a non-germ cell phenotype, including car- cinoma, carcinoid tumor, and sarcoma (Kelley and Scully, 1961; Peterson, 1957). With this study, we performed genetic analysis of eight MOT associated with malignant tumors of a non-germ cell phenotype to elucidate whether these malignant processes were in fact of germ cell origin. We previously confirmed a genotypic difference between homozygous MOT and heterozygous host tissue (Vortmeyer et al, 1999) in support of the original findings by Linder (Linder, 1969; Linder et al, 1975). In the present study, we detected genetic homozygosity in mature teratomatous tissues and associated malignancies with multiple genetic markers. The same allele was present in both the teratomatous and malignant component of the tumors. Occasionally, heterozygosity attributed to the process of meiotic recombination was detected in some of our cases (Vortmeyer et al, 1999). Our results clearly demonstrate the presence of the same homozygous genotype in MOT and associated malignancies of a non-germ cell phenotype, supporting a germ cell origin for these cancers.

Of particular interest is the angiosarcoma with omental metastasis and involvement of both ovaries in a 40-year-old woman. The right ovary disclosed two distinct cystic teratomas (MOT1 and MOT2), each composed of squamous epithelium and thyroid tissue. PCR analysis of both selectively microdissected histologic components of MOT1 and MOT2 repeatedly showed identical homozygous genotype within the individual tumors; however, the genetic changes between MOT1 and MOT2 were markedly different, suggesting the presence of two independent teratomas, as described previously (Carritt et al, 1982). Although genetically different, MOT1 and MOT2 appeared morphologically similar, indicating the role of possible local and environmental factors in the phe- 

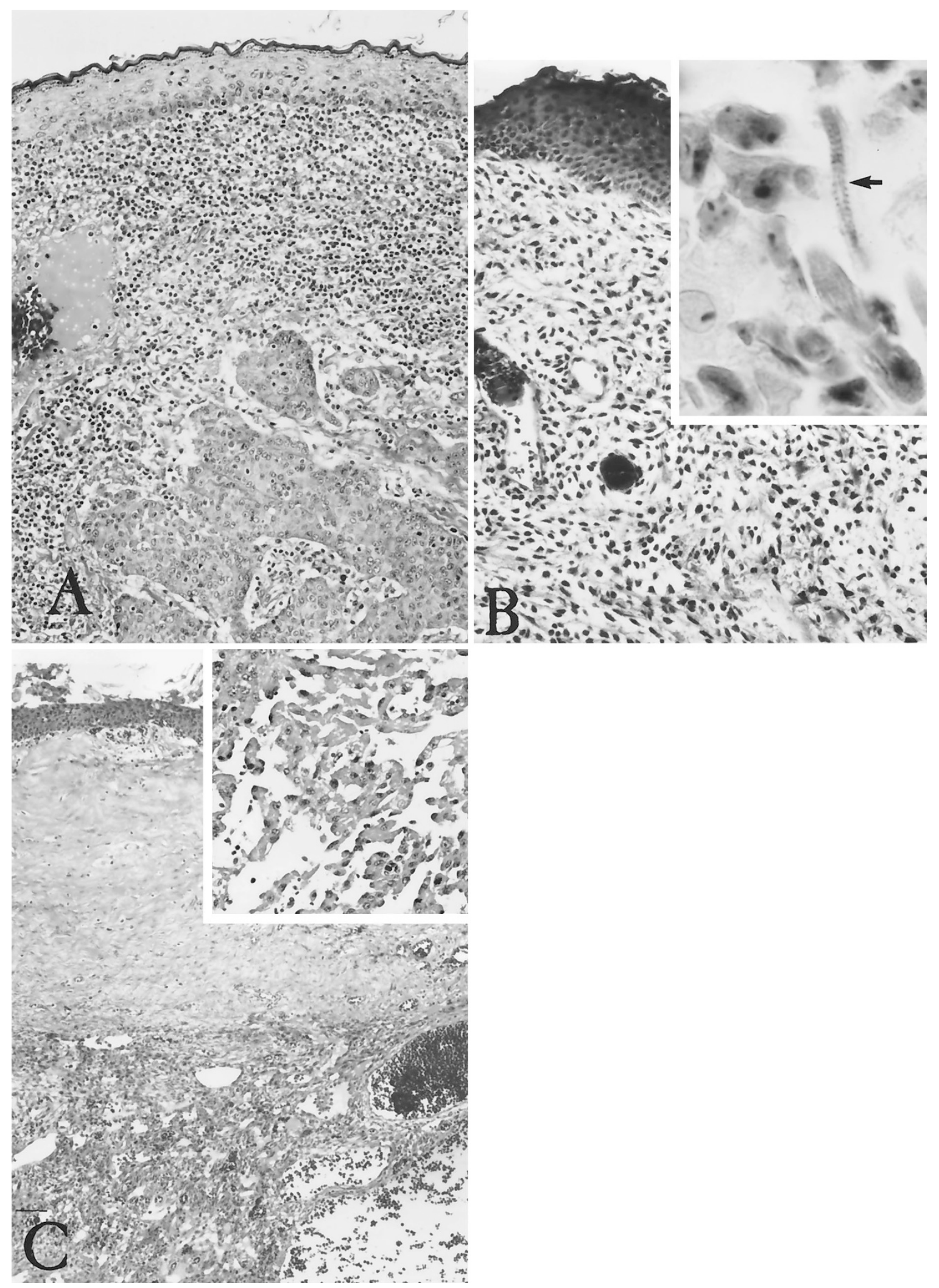

\section{Figure 1.}

Three examples of malignancies of a non-germ cell phenotype within mature ovarian teratomas (MOT). (A) Poorly differentiated carcinoma (bottom) associated with a mature teratoma with squamous epithelium (top) (hematoxylin and eosin; magnification, $\times 158$ ). (B) Embryonal rhabdomyosarcoma closely associated with a mature teratoma. The undifferentiated small cell neoplastic proliferation underlies the teratomatous squamous epithelium (hematoxylin and eosin; magnification, $\times 150$ ). Insert: Note the presence of cross striations in the tumor cells (arrow) (hematoxylin and eosin, magnification, $\times 1025)$. (C) Angiosarcoma associated with mature teratoma (hematoxylin and eosin; magnification, $\times 100$ ). Insert: Note the interconnecting vascular channels lined by sarcomatous cells (hematoxylin and eosin; magnification, $\times 150)$. 
$\begin{array}{llllll}1 & 2 & 3 & 4 & 5 & 6\end{array}$

A) D9S303

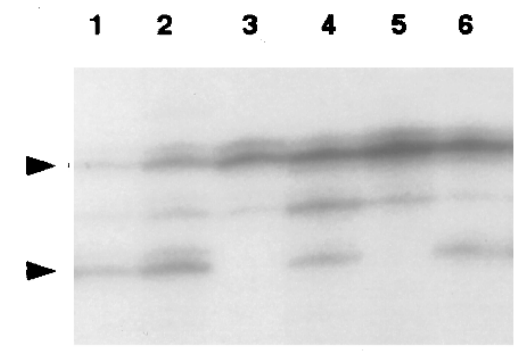

$\begin{array}{llllll}1 & 2 & 3 & 4 & 5 & 6\end{array}$

B) Ank-1
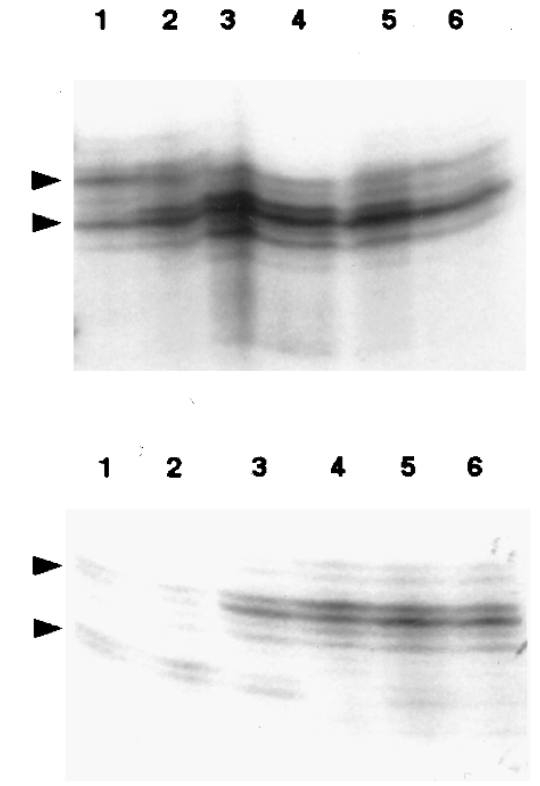

Figure 2.

Representative results of the PCR analysis in a teratoma with squamous cell carcinoma from patient 1 . The mature teratomatous squamous epithelium (lanes 3 and 4) and the squamous cell carcinoma (lanes 5 and 6) microdissected from the right ovary, showed an identical genotype. Both are homozygous with the presence of the upper allele only at the D9S303 locus (A), the lower allele only at the ANK1 locus (B), and the upper allele only at the CYP2D locus (C). The presence of a weaker lower allele with D9S303 and CYP2D was interpreted as contamination. Heterozygosity is retained in normal ovarian tissue (lanes 1 and 2).

notypic differentiation of ovarian germ cell tumors. The coexistent angiosarcoma also revealed a consistent homozygous genotype; however, the genetic profile obtained with multiple polymorphic markers was different from that of either MOT1 or MOT2. The consistent homozygosity of the angiosarcoma with all nine informative markers appeared to be pathogenetically related to teratomatous growth.

Ovarian sarcomas are rare, and their histogenesis is controversial. Some are thought to originate from ovarian connective tissue, whereas others may represent a component of a malignant mixed mullerian tumor or a teratoma (Talerman, 1996). The unidirectional differentiation of a teratoma (Talerman, 1996) or sarcomatous overgrowth in a benign teratoma (Nucci et al, 1998) could represent the mechanism of origin for the ovarian angiosarcoma in our case. Interestingly, a recent study of seven primitive ovarian angiosarcomas revealed an association with MOT in two cases (Nielson et al, 1997).
A) D9S303

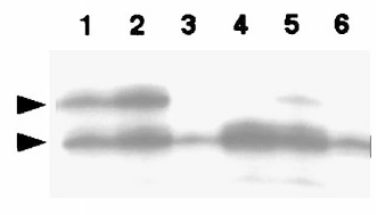

$\begin{array}{llllll}1 & 2 & 3 & 4 & 5 & 6\end{array}$

B) D3S2452

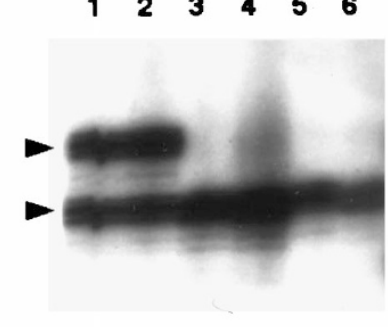

$2 \begin{array}{lllll}2 & 3 & 4 & 5 & 6\end{array}$

C) AR

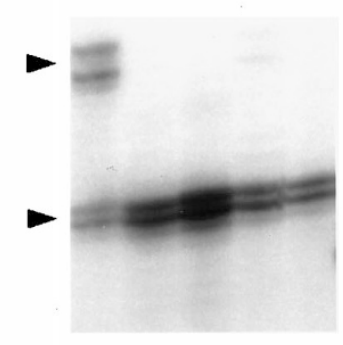

$\begin{array}{llllll}1 & 2 & 3 & 4 & 5 & 6\end{array}$

\section{D) $\mathbf{D 1 S 1 6 4 6}$}

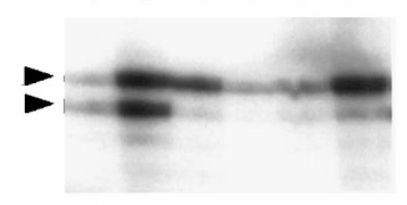

\section{Figure 3.}

Representative results of the PCR analysis in a teratoma with papillary thyroid carcinoma, follicular variant from patient 4 . Different areas of mature squamous epithelium (lanes 5 and 6 ) and different regions from papillary thyroid carcinoma (lanes 3 and 4) showed identical results. All different microdissected tissues were homozygous with the presence of the lower allele only at (A) D9S303, (B) D3S2452, (C) AR, and with the upper allele only at (D) D1S1646, while normal ovarian tissue (lanes 1 and 2) revealed the presence of both alleles.

In conclusion, tissue microdissection and genetic analysis with microsatellite markers in eight cases of MOT associated with malignancies of a non-germ cell phenotype suggest a common pathogenetic pathway for the teratomatous and malignant components. In various histologic types of malignancy involving mature teratomas of the ovary, we demonstrated the same genotype as that of mature teratomas, supporting a germ cell origin for these malignancies. We therefore conclude that some malignancies of non-germ cell phenotypes in the ovary fall into the spectrum of germ cell tumors.

\section{Materials and Methods}

\section{Tumor Samples}

Sixty-six MOT with associated malignancies of a nongerm cell phenotype were reviewed from the consul- 


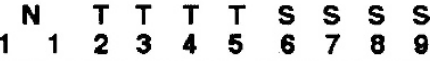

A) Ank-1

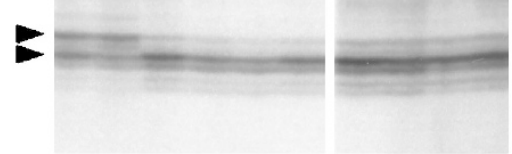

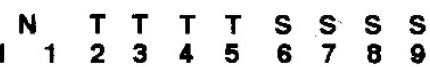

B) AR

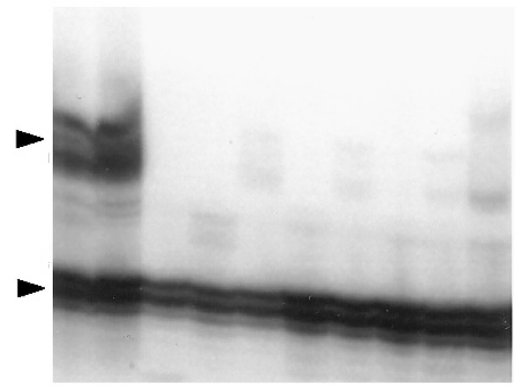

Figure 4.

Representative results of PCR analysis of tumor samples from patient 7. At ANK1 locus on chromosome 8 (A) and at AR gene locus on chromosome X (B) both mature teratoma (T: lanes 2 to 5 ) and rhabdomyosarcoma (S: lanes 6 to 9) revealed a homozygous pattern with the presence of the lower allele only while heterozygosity was retained in normal tissue (N: lane 1).

tation files of the Department of Gynecologic and Breast Pathology of the Armed Forces Institute of Pathology from 1965 to 1999. Eight cases with available paraffin blocks and normal tissue were selected for genetic analyses, to encompass a variety of histologic types of malignancies. The latter included squamous cell carcinomas $(n=4)$, sarcomas $(n=2)$, papillary thyroid carcinoma $(n=1)$, and carcinoid tumor $(n=1)$ (Table 1). Formalin-fixed, paraffinembedded tissue blocks were selected from normal adnexal control tissue, MOT, and associated malignancies for analysis. In case 8, the omental metastasis from the sarcoma was also analyzed.

\section{Sample Preparation and DNA Extraction}

Unstained 5-micron tissue sections on glass slides were deparaffinized with xylene, rinsed in graded ethanol (100\% to $80 \%)$, briefly stained with hematoxylin and eosin, and rinsed in 10\% glycerol in EDTA buffer. Normal tissue (ovarian stroma or fallopian tube) and different teratomatous components of each MT, as well as multiple samples from different areas of the malignancies (Table 1), were selectively microdissected from stained slides as described previously (Zhuang et al, 1995). Procured cells were immediately resuspended and incubated for 48 hours at $37^{\circ} \mathrm{C}$ in a 25- $\mu$ l solution containing $50 \mathrm{mM}$ Tris-hydrochloric acid ( $\mathrm{pH}$ 8.0), 1 mM EDTA, 0.5\% polyoxyethylene sorbitan monolaurate (Tween 20 ), and $0.5 \mathrm{mg} / \mathrm{ml}$ proteinase $\mathrm{K}$. The mixture was heated to $95^{\circ} \mathrm{C}$ for 5 minutes to inactivate the enzyme and was stored at $4^{\circ} \mathrm{C}$ until use.
A) Ank - 1

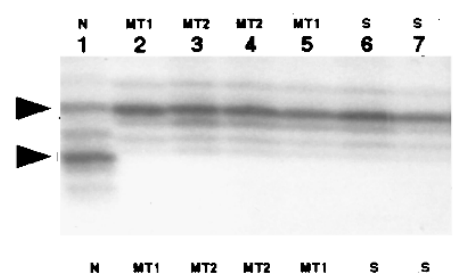

B) D1S1646

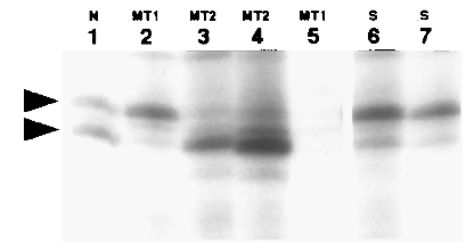

C) AR

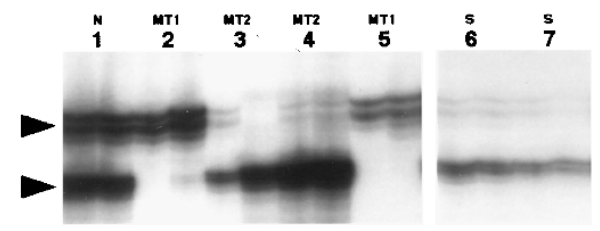

D) CYP2D

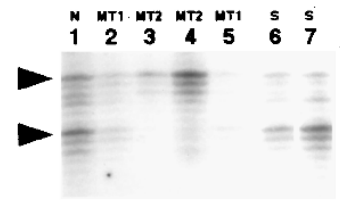

Figure 5.

Representative results of the PCR analysis in two mature teratomas (MT1 and MT2) and an angiosarcoma (S) from patient 8. (A) Homozygosity of different components of MT1 (MT1: lanes 2 and 5) and different components of MT2 (MT2: lanes 3 and 4) as well as different areas of the angiosarcoma in the right ovary (S: lane 6) and in the left ovary (S: lane 7) at the ANK1 locus on chromosome 8, whereas heterozygosity was retained in normal tissue ( $\mathrm{N}$ : lane 1). (B) At the D1S1646 locus, MT1 was homozygous with the presence of the upper allele (lane 2), whereas MT2 was homozygous with the presence of the lower allele (lanes 3 and 4). No amplification was obtained from one of samples of MT1 (lane 5). The DNA obtained from the angiosarcoma in the right (S: lane 6) and left ovary (S: lane 7) was homozygous with the presence of the upper allele only. The lower allele in these two samples was of lesser intensity in a ratio greater than $50 \%$ and was interpreted as contamination with non-tumoral DNA. (C) At the AR locus on chromosome $X$ (samples run in duplicate), whereas the normal tissue was heterozygous $(N)$, both components of MT1 (lanes 2 and 5) showed homozygosity with the presence of the upper allele, whereas both components of MT2 (lanes 3 and 4) demonstrated homozygosity of the opposite allele. Different areas of the angiosarcoma from the right ovary (S: lane 6) and left ovary (S: lane 7) showed a homozygous profile with the presence of the lower allele only. The presence of a weaker upper allele in lanes 6 and 7 corresponds to contamination. (D) At the CYP2D locus, MT1, MT2, and the angiosarcoma showed a different genotypic pattern, with the normal ovarian stroma (lane 1) being heterozygous. MT1 was heterozygous (lanes 2 and 5) and MT2 was homozygous with the presence of the upper allele only (lanes 3 and 4), whereas the angiosarcoma was homozygous with the presence of the lower allele only (lanes 6 and 7 ). The presence of a weaker upper allelic band in lanes 6 and 7 represents contamination.

\section{Genetic Analysis}

Using PCR, the samples were independently evaluated for heterozygosity at 6 to 10 chosen loci among 12 highly polymorphic microsatellite markers: D1S1646 (1p36), D2S1364 (2), D3S2452 (3p21.114.2), D7S1822 (7q31.1-31.2), ANK1 (8p21.1-11.2), D9S303 (9q), D9S171 (9p21), IFNA (9p22), INT2 (11q13), PYGM (11q13), CYP2D (22q13), and AR (Xq11.2-12). Locus-specific PCR assays were performed using a previously described procedure 
(Zhuang et al, 1995) in a total volume of $10 \mu$ l containing $1.5 \mathrm{mM} \mathrm{MgCl}_{2}, 1 \mu \mathrm{l}$ of 10X PCR buffer (Perkin Elmer, Norwalk, CT), $0.5 \cup$ Taq DNA polymerase, 1.25 $\mathrm{mM}$ each of the four standard nucleoside triphosphates, $0.4 \mu \mathrm{M}$ of each primer, $0.2 \mu \mathrm{l}$ of $\left.{ }^{32} \mathrm{P}\right] \mathrm{dCTP}$ $(6000 \mathrm{Ci} / \mathrm{mm})$, and $1.5 \mu \mathrm{l}$ of DNA. Thirty-five PCR cycles (template denaturation at $94^{\circ} \mathrm{C}$ for 1 minute, appropriate annealing temperature for 1 minute, and primer extension at $72^{\circ} \mathrm{C}$ for 1 minute) were carried out. The amplified DNA was diluted 1:1 with loading dye (12 mm EDTA, 0.1\% bromophenol blue, and $0.1 \%$ xylene cyanol in formamide), denatured at $94^{\circ} \mathrm{C}$ for 4 minutes, loaded onto $8 \%$ polyacrylamide gels (Gel Mix 8; Life Technologies, Gaithersburg, MD) and subjected to electrophoresis at $60 \mathrm{~W}$ for an average of 100 minutes. Gels were transferred onto Whatman $3 \mathrm{MM}$ paper and dried, and autoradiography was performed with Kodak X-OMAT film (Eastman Kodak, Rochester, NY).

\section{References}

Carritt B, Parrington M, Welch HM, and Povey S (1982). Diverse origins of multiple ovarian teratomas in a single individual. Proc Natl Acad Sci USA 79:7400-7404.

Devaney K, Snyder R, Norris HJ, and Tavassoli FA (1993). Proliferative and histologically malignant struma ovarii: A clinicopathologic study of 54 cases. Int J Gynecol Pathol 12:333-343.

Hirakawa T, Tsuneyoshi M, and Enjoji M (1989). Squamous cell carcinoma arising in mature cystic teratoma of the ovary: Clinicopathologic and topographic analysis. Am J Surg Pathol 13:397-405.

Kelley RR and Scully RE (1961). Cancer developing in dermoid cysts of the ovary: A report of 8 cases, including a carcinoid and a leiomyosarcoma. Cancer 14:989-1000.

Klionsky BL, Nickens OJ, and Amortegui AJ (1972). Squamous cell carcinoma in situ arising in adult cystic teratoma of the ovary. Arch Pathol 93:161-3.

Ladanyi M, Samaniego F, Reuter VE, Motzer RJ, Jhanwar SC, Bosl GJ, and Chaganti RSK (1990). Cytogenetic and immunohistochemical evidence for the germ cell origin of a subset of acute leukemias associated with mediastinal germ cell tumors. J Natl Cancer Inst 82:221-227.
Liberati F, Maccio T, Ascani S, Farabi R, Lancia D, Peciarolo A, and Bolis GB (1998). Primary malignant melanoma arising in an ovarian cystic teratoma. Acta Oncol 37:381-383.

Linder D (1969). Gene loss in human teratomas. Proc Natl Acad Sci USA 63:699-704.

Linder D, McCaw BK, and Hecht F (1975). Parthenogenic origin of benign ovarian teratomas. New Engl J Med 292:6366.

Nielson GP, Young RH, Prat J, and Scully RE (1997). Primary angiosarcoma of the ovary: A report of seven cases and review of the literature. Int J Gynecol Pathol 16:378-382.

Nucci MR, Krausz T, Lifschitz-Mercer B, Chan JKC, and Fletcher CDM (1998). Angiosarcoma of the ovary: Clinicopathologic and immunohistochemical analysis of four cases with a broad morphologic spectrum. Am J Surg Pathol 22:620-630.

Peterson WF (1957). Malignant degeneration of benign cystic teratomas of the ovary: collective review of literature. Obstet Gynecol Surv 12:793-830.

Russell P and Farnsworth A (1997). Teratomas-mature. In: Russel P, editor. Surgical pathology of the ovaries. New York: Churchill Livingstone, 519-532.

Seifer DB, Weiss LM, and Kempson RL (1986). Malignant lymphoma arising within thyroid tissue in a mature cystic teratoma. Cancer 58:2459-2461.

Talerman A (1996). Nonspecific tumors of the ovary, including mesenchymal tumors and malignant lymphoma, 4th ed. In: Kurman RJ, editor. Blaustein's pathology of the female genital tract. New York: Springer-Verlag, 915-937.

Vortmeyer AO, Devouassoux-Shisheboran M, Li G, Mohr V, Tavassoli F, and Zhuang Z (1999). Microdissection-based analysis of mature ovarian teratomas. Am J Pathol 154:987991.

Zhuang Z, Bertheau P, Emmert-Buck M, Liotta L, Gnarra J, Linehan W, and Lubensky I (1995). A microdissection technique for archival DNA analysis of specific cell populations in lesions $<1 \mathrm{~mm}$ in size. Am J Pathol 146:620-625. 